\title{
COMPORTAMENTO DE CULTIVARES DE FEIJOEIRO COMUM À MURCHA-DE-CURTOBACTERIUM*
}

\author{
ANTONIO CARLOS MARINGONI** \\ Departamento de Produção Vegetal, Faculdade de Ciências Agronômicas - UNESP, Cx. Postal 237, CEP 18.603-970, \\ Botucatu, São Paulo, e-mail: maringoni@fca.unesp.br
}

(Aceito para publicação em 18/01/2002)

MARINGONI, A.C. Comportamento de cultivares de feijoeiro comum à murcha-de-Curtobacterium. Fitopatologia Brasileira 27:157-162. 2002.

\section{RESUMO}

No presente trabalho foi avaliada a resistência de 40 cultivares de feijoeiro comum (Phaseolus vulgaris) à murcha-deCurtobacterium, inoculadas separadamente com dois isolados de Curtobacterium flaccumfaciens pv. flaccumfaciens, e o desenvolvimento da parte aérea de cultivares resistentes e suscetíveis a essa doença, inoculadas ou não com um isolado da bactéria. As reações apresentadas pelas cultivares permitiram verificar que 'IAC Carioca Aruã', 'IAC Carioca Akytã' e 'IAC Carioca Pyatã' foram resistentes e que 'A - 768', 'Aeté', 'Aporé', 'Bambuí', 'Bico de Ouro', 'BR IPA 11 - Brígida', 'Carioca MG', 'Carioquinha', 'Catu', 'Corrente', 'Diamante Negro', 'FT Bonito', 'FT Nobre', 'FT-120',
'IAC Carioca', 'IAC Maravilha', 'IAC Una', 'IAPAR 14', 'IAPAR 16', 'IAPAR 31', 'IAPAR 44', 'IPA 6', 'Iraí', 'Jalo Precoce', 'Jamapa', 'Onix', 'Ouro Negro', 'Pérola', 'R - 161', 'RAO 33', 'Rio Tibagi', 'Rosinha G2', 'Roxo 90', 'Rudá', 'Safira', 'Tarumã' e 'Xamego' foram suscetíveis à murcha-de-Curtobacterium. Plantas de feijoeiro das cultivares resistentes (IAC Carioca Aruã, IAC Carioca Akytã e IAC Carioca Pyatã) apresentaram menor redução da matéria seca da parte aérea do que das suscetíveis (IAC Carioca e Pérola), quando inoculadas com C. flaccumfaciens pv. flaccumfaciens.

Palavras-chave adicionais: Phaseolus vulgaris, Curtobacterium flaccumfaciens pv. flaccumfaciens, resistência.

\section{ABSTRACT \\ Behaviour of dry bean cultivars to bacterial wilt}

The objective of this research was to evaluate the reaction of 40 dry bean (Phaseolus vulgaris) cultivars inoculated with two isolates of Curtobacterium flaccumfaciens pv. flacummfaciens, and the shoot dry weight of resistant and susceptible dry bean cultivars inoculated or not with this bacteria. The cultivars IAC Carioca Aruã, IAC Carioca Akytã, and IAC Carioca Pyatã were resistant, whereas the following cultivars were susceptible to bacterial wilt: A - 768, Aeté, Aporé, Bambuí, Bico de Ouro, BR IPA 11 Brígida, Carioca MG, Carioquinha, Catu, Corrente, Diamante
Negro, FT Bonito, FT Nobre, FT-120, IAC Carioca, IAC Maravilha, IAC Una, IAPAR 14, IAPAR 16, IAPAR 31, IAPAR 44, IPA 6 , Iraí, Jalo Precoce, Jamapa, Onix, Ouro Negro, Pérola, R - 161, RAO 33, Rio Tibagi, Rosinha G2, Roxo 90, Rudá, Safira, Tarumã, and Xamego. Plants of resistant dry bean cultivars (IAC Carioca Aruã, IAC Carioca Akytã, and IAC Carioca Pyatã) had a smaller reduction of shoot dry weight than susceptible cultivars (IAC Carioca and Pérola) when inoculated with C. flaccumfaciens pv. flaccumfaciens.

\section{INTRODUÇÃO}

A cultura do feijoeiro comum (Phaseolus vulgaris L.) é afetada por vários tipos de patógenos que causam doenças e acarretam perdas significativas na produção. Segundo Saettler (1991), os principais patógenos bacterianos que ocorrem em várias localidades do mundo são: Xanthomonas axonopodis pv. phaseoli (Smith 1897) Vauterin et al. 1995, Pseudomonas savastanoi pv. phaseolicola (Burkholder 1926) Gardan et al. 1992, Pseudomonas syringae pv. syringae van Hall 1902, Pseudomonas syringae pv. tabaci (Wolf \& Foster) Young et al. 1978 e Curtobacterium flaccumfaciens pv. flaccumfaciens (Hedges 1922) Collins \& Jones 1983. Há relatos da ocorrência

\footnotetext{
*Parte da tese de Livre-docência. Faculdade de Ciências Agronômicas, UNESP. (2000)

** Bolsista do CNPq
}

de Ralstonia solanacearum (Smith 1896) Yabuuchi et al. 1995 em feijoeiro no Brasil, conforme Robbs et al. (1982). Dos patógenos listados por Saettler (1991), até 1981, somente $P$. savastanoi pv. phaseolicola e C. flaccumfaciens pv. flaccumfaciens ainda não tinham sido relatados no país (Robbs et al., 1982). A constatação de C. flaccumfaciens pv. flaccumfaciens (Cff) somente foi relatada em 1995 no Estado de São Paulo. (Maringoni \& Ros a,1997).

Os sintomas típicos da doença em feijoeiro são principalmente murcha, escurecimento vascular e morte da parte aérea (Hedges, 1926). A murcha na parte aérea é devido à falha no transporte de seiva provocada pela degradação das paredes dos vasos de xilema (Dinesen, 1978).

No feijoeiro comum, algumas medidas são preconizadas para o controle da murcha-de-Curtobacterium. O emprego de sementes sadias, já que o patógeno sobrevive e é transmitido por sementes (Saettler \& Perry, 1972), tem sido adotado em 


\section{A.C. Maringoni}

alguns países, através da certificação sanitária. Esta medida foi tão eficaz que durante 20 anos a murcha-de-Curtobacterium não foi constatada em áreas de produção de Dakota do Norte e em Minessota, E.U.A., e que apenas em 1994 Cff foi isolado de uma amostra de sementes utilizada por um agricultor daquela região (Venette et al., 1995).

Várias pesquisas foram iniciadas no final da década de 50 e no início da década de 60, visando selecionar fontes de resistência em feijoeiro à murcha-de-Curtobacterium. Estudos pioneiros desenvolvidos por Coyne et al. (1963), para verificar a reação de 1.067 introduções de feijoeiro à murcha-deCurtobacterium, evidenciaram que o PI 165.078 de feijoeiro comum e a variedade G.N. Nebraska \# 1 apresentaram níveis satisfatórios de resistência à doença.

Estudos genéticos da resistência de feijoerio à murchade-Curtobacterium, em vários cruzamentos, têm demonstrado que a herança é de natureza poligênica (Coyne et al., 1965; Coyne et al., 1966).

Na literatura internacional, há indicação da resistência em algumas cultivares e linhagens de feijoeiro à murcha-deCurtobacterium. Entre elas destacam-se: 'G.N. Emerson' (Coyne \& Schuster, 1974), 'G-12/965', 'G-16/965', 'G-10/968' (Phang et al., 1974), 'G.N. 123', 'Pearlgreen', 'Snocorop', 'Maxidor', 'Romulus' (Nikitina et al., 1980), 'Rositsa' (Karkmkova \& Boyadzhiev, 1984) e 'Porrilho Sintético' (Chavarro et al., 1985). Inexistem relatos sobre o comportamento de cultivares de feijoeiro brasileiras a essa enfermidade. O presente trabalho objetivou avaliar o comportamento de 40 genótipos de feijoeiro comum a dois isolados de Cff, sob condições de casa de vegetação, e o desenvolvimento da parte aérea de plantas de genótipos resistentes e suscetívies à murcha-deCurtobacterium, inoculadas ou não com um isolado de Cff.

\section{MATERIAL E MÉTODOS}

\section{Avaliação da resistência de cultivares de feijoeiro comum à murcha-de-Curtobacterium}

Três ensaios foram conduzidos sob condições de telado, visando avaliar a reação de diferentes cultivares de feijoeiro à murcha-de-Curtobacterium, através da inoculação de plantas de feijoeiro com dois isolados (Feij - 2625; colônias de cor salmão e Feij - 2634; colônias de cor amarela) de Cff.

No ensaio 1, empregaram-se as cultivares de feijoeiro IAC Carioca Pyatã, IAC Carioca Akytã, IAC Carioca Aruã, IAC Una, IAC Maravilha, Aporé, Safira, FT-120, Carioca MG, Diamante Negro, Jalo Precoce, Pérola, Carioquinha e IAC Carioca e os sintomas da doença foram avaliados aos 28 dias após a inoculação; no ensaio 2, as cultivares de feijoeiro utilizadas foram FT Bonito, FT Nobre, BR IPA 11, Brígida, Bico de Ouro, Iraí, IAPAR 14, IAPAR 44, Onix, Rudá, Rosinha G2, Xamego e IAC Carioca e os sintomas da doença foram avaliados aos 25 dias após a inoculação; no ensaio 3, empregaram-se as cultivares de feijoeiro A - 768, R - 161, Ouro Negro, Corrente, Rio Tibagi, IPA 6, RAO 33, Bambuí, Roxo 90, IAPAR 31, Tarumã, Aeté, Catu, Jamapa, IAPAR 16 e IAC Carioca e os sintomas da doença foram avaliados aos 25 dias após a inoculação.

As plântulas de feijoeiro foram cultivadas em vasos, contendo o volume aproximado de 21 de substrato autoclavado constituído da mistura de terra, esterco de curral curtido e areia grossa lavada (1:2:1), além de adubo químico e calcáreo dolomítico (Torres \& Maringoni, 1999). Em cada vaso foram mantidas três plantas e, aos nove dias após a emergência, foram inoculadas, através de duas punções no caule, entre as folhas cotiledonares e as folhas primárias, com uma agulha entomológica previamente umedecida em colônias bacterianas, desenvolvidas em meio de cultura nutrientesacarose-ágar, durante $96 \mathrm{~h}$ a $28{ }^{\circ} \mathrm{C}$. No tratamento testemunha, as plantas de feijoeiro da cultivar IAC Carioca ao invés de inóculo bacteriano receberam água destilada.

Para cada um dos isolados de Cff foram inoculadas as plantas de cada cultivar de feijoeiro, aos nove dias após a emergência, contidas em quatro vasos e mantidas sob condições de telado, com temperatura oscilando entre 20 a 30 ${ }^{\circ} \mathrm{C}$ e umidade relativa entre 70 a $90 \%$. Cada parcela experimental foi constituída por um vaso contendo três plantas. O delineamento experimental utilizado foi o blocos ao acaso com quatro repetições. As plantas foram irrigadas diariamente e pulverizadas semanalmente com defensivos agrícolas registrados para a cultura, visando o controle de ácaros e insetos.

Os sintomas da doença foram avaliados através da adaptação da escala de notas empregada para murcha-deFusarium, recomendada pelo CIAT (Centro Internacional de Agricultura Tropical), descrita por Schoonhven \& Pastor-Corrales (1987), que se segue: $0=$ sem sintomas de doença; 1 = sintoma de mosaico nas folhas; 2 = muito pouca folhas murchas (1 a 3 folhas, menos de $10 \%$ das folhas da planta); 5 = aproximadamente $25 \%$ de folhas apresentam murchas e amarelecimento; $7=$ aproximadamente $50 \%$ de folhas murchas, amarelecimento e necrose de folíolos, plantas com nanismo; $9=$ aproximadamente $75 \%$ ou mais de folhas com murcha e/ou necrose, queda prematura de folhas, nanismo severo e ou morte da planta. As reações de resistência e de suscetibilidade foram consideradas, respectivamente, para notas médias de severidade até 2 e superiores a 2,1 .

Colonização dos vasos do xilema em plantas de feijoeiro comum inoculadas com Curtobacterium flaccumfaciens pv. flaccumfaciens

Foram retirados fragmentos de caule das cultivares IAC Carioca e Carioquinha entre as folhas primárias e a segunda folha trifoliada, de plantas inoculadas com os isolados Feij - 2625 (IAC Carioca) e Feij - 2634 (Carioquinha), aos 28 dias após a inoculação no ensaio 1 . Sob microscópio esterioscópico, esses fragmentos foram cortados, visando expor tecidos do xilema. Posteriormente, os fragmentos de tecidos foram preparados conforme Maringoni (2000) e as amostras examinadas e fotografadas em microscópio eletrônico de varredura, marca Philips, modelo SEM 515, sob tensão de $20 \mathrm{KV}$. 
Comportamento de cultivares de feijoeiro comum inoculadas e não-inoculadas com Curtobacterium flaccumfaciens pv. flaccumfaciens

Dois ensaios foram conduzidos simultaneamente com as cultivares de feijoeiro IAC Aruã, IAC Akytã , IAC Pyatã, Pérola e IAC Carioca, com e sem inoculação das plantas com o isolado Feij - 2625 de Cff.

As plantas foram cultivadas em vasos de $81 \mathrm{de}$ capacidade, contendo substrato autoclavado, sendo mantidas sob condições de casa de vegetação, com controle parcial de temperatura $\left(25\right.$ a $\left.32^{\circ} \mathrm{C}\right)$ e umidade relativa $(70$ a $90 \%)$. As plantas foram conduzidas e inoculadas de forma semelhante ao ensaio de avaliação da resistência de cultivares de feijoeiro à murcha-de-Curtobacterium. Plantas não-inoculadas foram tratadas semelhantemente com água destilada.

Cada parcela, nos dois ensaios, foi constituída de um vaso contendo três plantas. $\mathrm{O}$ delineamento experimental utilizado foi o blocos ao acaso, com cinco repetições

Trinta e um dias após a inoculação, procedeu-se a avaliação dos sintomas da doença nas plantas, com a escala de notas anteriormente descrita e coletou-se a parte aérea das plantas de cada parcela, dos dois ensaios, visando determinar a matéria seca. Para isto, as plantas foram transferidas para sacos de papel e mantidas em estufa com circulação ar forçada, à temperatura de $60{ }^{\circ} \mathrm{C}$, durante um período aproximado de $72 \mathrm{~h}$, até a massa manter-se constante.

Os dados obtidos foram submetidos à análise de variância e as médais comparadas pelo teste de Tukey ao nível de $5 \%$ de propabilidade.

\section{RESULTADOS E DISCUSSÃO}

Verifica-se no ensaio 1 (Tabela 1) que a maioria das cultivares avaliadas foram suscetíveis à murcha-deCurtobacterium. Considerando-se resistentse aquelas cultivares que apresentaram um índice médio de severidade igual ou inferior a dois, apenas IAC Carioca Aruã, IAC Carioca Pyatã e IAC Carioca Akytã apresentaram reação de resistência à doença, quando inoculadas com os isolados Feij -2525 (IAC Carioca Pyatã e IAC Carioca Akytã) e Feij - 2634 (IAC Carioca Aruã, IAC Carioca Pyatã e IAC Carioca Akytã). Nos ensaios 2 e 3 (Tabelas 2 e 3 ) todas as cultivares testadas foram suscetíveis.

Os dados aqui observados demonstram alta suscetibilidade da maioria das cultivares de feijoeiro avaliadas à murcha-de-Curtobacterium. Esse fato indica uma ameaça grave à cultura do feijoeiro comum no país, pois essa doença poderá tornar-se problemática para cultivares suscetíveis, em condições favoráveis à ocorrência de epidemias em campo. Pelo menos para o Estado de São Paulo, tem-se o conhecimento da ocorrência sistemática de focos de epidemias da murcha-de-Curtobacterium, em lavouras conduzidas na região do Vale do Paranapanema (Maringoni, 2000).

Não existem relatos sobre o comportamento de cultivares nacionais de feijoieiro comum a essa doença. Os dados aqui relatados são inéditos e poderão auxiliar o programa de melhoramento genético da cultura, frente às
TABELA 1 - Severidade da murcha-de-Curtobacterium em cultivares de feijoeiro comum (Phaseolus vulgaris) inoculadas com dois isolados de Curtobacterium flaccumfaciens pv. flaccumfaciens (ensaio 1)

\begin{tabular}{|c|c|c|c|}
\hline Cultivar & Feij - 2625 & Feij - 2634 & Reação ${ }^{3}$ \\
\hline IAC Carioca Pyatã & $0,67^{1}$ & 0,50 & $\mathrm{R}$ \\
\hline IAC Carioca Akytã & 0,67 & 0,58 & $\mathrm{R}$ \\
\hline IAC Carioca Aruã & $-^{2}$ & 1,92 & $\mathrm{R}$ \\
\hline IAC Una & 9,00 & 8,67 & S \\
\hline IAC Maravilha & 8,50 & 8,50 & S \\
\hline Aporé & 8,83 & 8,67 & S \\
\hline Safira & 8,50 & 8,17 & S \\
\hline FT-120 & 8,83 & 8,83 & S \\
\hline Carioca MG & 8,83 & 8,67 & S \\
\hline Diamante Negro & 9,00 & 9,00 & S \\
\hline Jalo Precoce & 8,67 & 8,50 & S \\
\hline Pérola & 9,00 & 8,67 & S \\
\hline Carioquinha & 9,00 & 9,00 & $S$ \\
\hline IAC Carioca & 8,50 & 8,50 & S \\
\hline IAC Carioca (testemunha) & a) 0 & 0 & - \\
\hline
\end{tabular}

${ }^{1}$ Valor médio de severidade de quatro repetições (notas de 0 a 9 ). ${ }^{2} \mathrm{R}=$ resistente e $\mathrm{S}=$ suscetível

${ }^{3}$ Não avaliado.

reações apresentadas pelas cultivares avaliadas.

Acredita-se que, pelo menos, um dos progenitores das cultivares IAC Carioca Aruã, IAC Carioca Akytã e IAC Carioca Pyatã possua resistência à murcha-de- Curtobacterium pois, segundo Pompeu (1994), a cultivar IAC Carioca Pyatã é originária da linhagem H853-50-2, geração F3 do cruzamento Dor 41 x (10-3-1. TU 1B1-2.10-9-1). A cultivar IAC Carioca Aruã é originária da linhagem H8522-50-2, da seleção efe-

TABELA 2 - Severidade da murcha-de-Curtobacterium em cultivares de feijoeiro comum (Phaseolus vulgaris) inoculadas com dois isolados de Curtobacterium flaccumfaciens pv. flaccumfaciens (ensaio 2)

\begin{tabular}{lccc}
\hline Cultivar & Feij - 2625 & Feij - 2634 & Reaçã $^{\mathbf{2}}$ \\
\hline FT Bonito & $9,00^{1}$ & 9,00 & $\mathrm{~S}$ \\
FT Nobre & 9,00 & 9,00 & $\mathrm{~S}$ \\
BR IPA 11 - Brígida & 9,00 & 9,00 & $\mathrm{~S}$ \\
Bico de Ouro & 9,00 & 8,83 & $\mathrm{~S}$ \\
Iraí & 9,00 & 9,00 & $\mathrm{~S}$ \\
IAPAR 14 & 9,00 & 9,00 & $\mathrm{~S}$ \\
IAPAR 44 & 8,83 & 8,50 & $\mathrm{~S}$ \\
Onix & 8,67 & 8,17 & $\mathrm{~S}$ \\
Rudá & 9,00 & 9,00 & $\mathrm{~S}$ \\
Rosinha G2 & 9,00 & 9,00 & $\mathrm{~S}$ \\
Xamego & 8,67 & 8,33 & $\mathrm{~S}$ \\
IAC Carioca & 8,50 & 8,17 & $\mathrm{~S}$ \\
IAC Carioca (testemunha) & 0 & 0 & - \\
\hline
\end{tabular}

${ }^{1}$ Valor médio de severidade de quatro repetições (notas de 0 a 9 ).

${ }^{2} \mathrm{~S}=$ Suscetível 
TABELA 3 - Severidade da murcha-de-Curtobacterium em cultivares de feijoeiro comum (Phaseolus vulgaris) inoculadas com dois isolados de Curtobacterium flaccumfaciens pv. flaccumfaciens (ensaio 3)

\begin{tabular}{|c|c|c|c|}
\hline Cultivar & Feij - 2625 & Feij - 2634 & Reação \\
\hline$A-768$ & $9,00^{1}$ & 8,17 & $\mathrm{~S}$ \\
\hline $\mathrm{R}-161$ & 8,17 & 7,67 & $S$ \\
\hline Ouro Negro & 9,00 & 8,83 & S \\
\hline Corrente & 8,00 & 7,00 & $S$ \\
\hline Rio Tibagi & 8,67 & 7,84 & $S$ \\
\hline IPA 6 & 8,83 & 8,17 & S \\
\hline RAO 33 & 7,17 & 6,17 & $S$ \\
\hline Bambuí & 9,00 & 7,84 & $S$ \\
\hline Roxo 90 & 9,00 & 8,33 & $S$ \\
\hline IAPAR 31 & 7,50 & 6,83 & S \\
\hline Tarumã & 9,00 & 8,83 & $S$ \\
\hline Aeté & 9,00 & 8,33 & $S$ \\
\hline Catu & 9,00 & 6.67 & $S$ \\
\hline Jamapa & 7,50 & 7,50 & $S$ \\
\hline IAPAR 16 & 9,00 & 8,00 & $S$ \\
\hline IAC Carioca & 8,67 & 8,50 & $S$ \\
\hline IAC Carioca (testemunha) & a) 0 & 0 & - \\
\hline
\end{tabular}

${ }^{1}$ Valor médio de severidade de quatro repetições (notas de 0 a 9). ${ }^{2} \mathrm{~S}=$ suscetível

tuada na geração F4 do cruzamento (10771.122) x (H538041.A156) x (H5380-41.AB136) e a cultivar IAC Carioca Akytã é oriunda da linhagem H853-50-6, da seleção efetuada na geração F3 do cruzamento DOR 41 x (10-3-1.TU1B1-2.103-1), conforme Pompeu (1996). Essas três cultivares de feijoeiro foram selecionadas para a resistência à antracnose e ao vírus do mosaico comum do feijoeiro (Bean common mosaic virus, BCMV) família Potyviridae, gênero Potyvirus e em condições de campo apresentam bons níveis de resistência à mancha angular e à ferrugem (Pompeu, 1994; Pompeu, 1996).

Supunha-se que algumas cultivares de feijoeiro que apresentassem resistência ao crestamento bacteriano comum, tais como Iapar 14, Iapar 16 e Iapar 31 (Rava \& Sartorato, 1994; Maringoni, 1998; Torres \& Maringoni, 1999) tivessem algum nível de resistência à murcha-de-Curtobacterium, porém esta hipótese não foi confirmada (Tabelas 2 e 3). Isto indicou que os genes que conferem resistência ao crestamento bacteriano comum são diferentes daqueles que condicionam resistência à murcha-de-Curtobacterium.

Conforme Schuster et al. (1964) e Halluka et al. (1978), a resistência condicionada em alguns genótipos de feijoeiro à murcha-de-Curtobacterium é caracterizada pela menor quantidade de bactéria nos tecidos, indicando existir algum tipo de mecanismo na planta que dificulta a colonização.

Nas cultivares Carioquinha e IAC Carioca, suscetíveis à murcha-de-Curtobacterium, foi constatada a presença de grande quantidade de células bacterianas colonizando o xilema (Figura 1), concordando com as observações de Dinesen (1978) que, através de exames citológicos, sob microscopia eletrônica, constatou que Cff colonizou apenas vasos de xilema, e com Schuster et al. (1964) que verificaram grande quantidade de Cff em tecidos de plantas suscetíveis.

Os resultados do comportamento das cultivares de feijoeiro inoculadas ou não-inoculadas com o isolado Feij-2625 de Cff, aos 31 dias após a inoculação (Tabela 4), confirmaram a resistência das cultivares feijoeiro IAC Carioca Aruã, IAC Carioca Pyatã e IAC Carioca Akytã à murcha-deCurtobacterium, pela baixa severidade apresentada pelas plantas inoculadas com o isolado de Cff. As plantas nãoinoculadas das cultivares IAC Carioca Aruã, IAC Carioca Pyatã, IAC Carioca Akytã e Pérola apresentaram maior matéria seca média da parte aérea do que a cultivar IAC Carioca. Quando inoculadas, plantas das cultivares IAC Carioca Aruã, IAC Carioca Pyatã e IAC Carioca Akytã apresentaram maior matéria seca média da parte aérea do que as cultivares Pérola e IAC Carioca (Tabela 4).

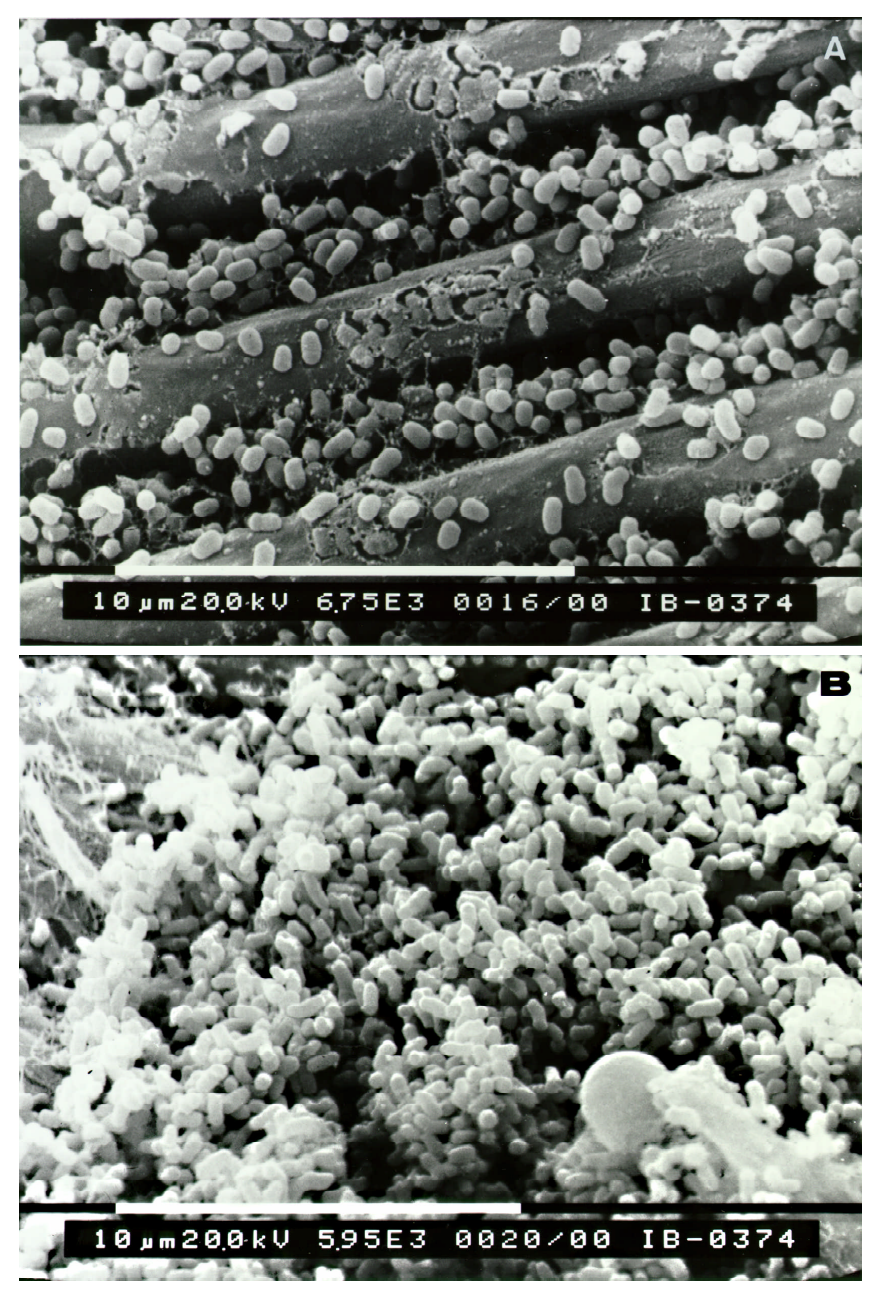

FIG. 1 - Micrografia eletrônica de varredura de secções de vasos de xilema de caules de feijoeiro comum(Phaseolus vulgaris) das cultivares Carioquinha (A) e IAC Carioca (B) colonizados por Curtobacterium flaccumfaciens pv. flaccumfaciens, aos vinte e oito dias após a inoculação. 
TABELA 4 - Comportamento de cinco cultivares de feijoeiro comum inoculadas ou não-inoculadas com o isolado Feij - 2625 de Curtobacterium flaccumfaciens pv. flaccumfaciens, aos trinta e um dias após a inoculação

\begin{tabular}{|c|c|c|c|c|c|}
\hline Cultivar & $\begin{array}{c}\text { Severidade dos } \\
\text { sintomas em } \\
\text { plantas não } \\
\text { inoculadas } \\
\end{array}$ & $\begin{array}{c}\text { Severidade dos } \\
\text { sintomas em } \\
\text { plantas } \\
\text { inoculadas } \\
\end{array}$ & $\begin{array}{l}\text { Matéria seca } \\
\text { média (g) de } \\
\text { plantas não } \\
\text { inoculadas }\end{array}$ & $\begin{array}{c}\text { Matéria seca } \\
\text { média (g) de } \\
\text { plantas } \\
\text { inoculadas }\end{array}$ & $\begin{array}{c}\text { Redução da } \\
\text { matéria seca } \\
(\%)\end{array}$ \\
\hline IAC Carioca Akytã & $0^{1}$ & $0,53^{1}$ & $15,70 \mathrm{a}^{2}$ & $7,74 \mathrm{a}^{2}$ & 50,7 \\
\hline IAC Carioca Aruã & 0 & 0,87 & $16,54 \mathrm{a}$ & $9,25 \mathrm{a}$ & 44,1 \\
\hline IAC Carioca Pyatã & 0 & 0,33 & $14,69 \mathrm{a}$ & $7,13 \mathrm{a}$ & 48,5 \\
\hline Pérola & 0 & 8,67 & $16,57 \mathrm{a}$ & $3,19 \mathrm{~b}$ & 80,7 \\
\hline IAC Carioca & 0 & 8,60 & $9,77 \mathrm{~b}$ & $3,01 \mathrm{~b}$ & 69,2 \\
\hline
\end{tabular}

${ }^{1}$ Valor médio de severidade de cinco repetições (notas de 0 a 9 ).

${ }^{2}$ Médias seguidas da mesma letra não diferem entre si pelo teste de Tukey a $5 \%$.

Estes resultados demonstraram que as cultivares resistentes à murcha-de-Curtobacterium, uma vez inoculadas com o isolado Feij-2625, apresentaram melhor desenvolvimento da parte aérea do que as cultivares suscetíveis (Tabela 4). Calculando-se a redução da matéria seca da parte aérea devida à colonização por Cff, foi constatada a redução na ordem de 69,2 a 80,7 \%, para as cultivares suscetívies, e de 44,1 a $50,7 \%$, para as cultivares resistentes (Tabela 4). A menor redução da matéria seca nas cultivares resistentes, quando inoculadas com Cff, indicou a existência de um provável mecanismo de resistência que dificultou e/ou retardou a colonização dos vasos do xilema pela bactéria. Essa hipótese é levantada em função das observações de Schuster et al. (1964) e Halluka et al. (1978), os quais constataram menor quantidade de bactérias em tecidos de plantas de feijoeiro resistentes, quando comparada com tecidos de plantas suscetíveis, submetidas à inoculação artificial. Sob condições de campo, empregando uma mistura de três isolados de Cff de Zornia glabra (Desv.), Chavarro et al. (1985) obtiveram redução aproximada de $37 \%$ da matéria seca da parte aérea na cultivar de feijoeiro Porrillo Sintetico, considerada resistente à murcha-de-Curtobacterium, e de $81 \%$ em Z. glabra cultivar CIAT 7847, suscetível à murcha-deCurtobacterium, quando comparadas com os controles nãoinoculados.

\section{AGRADECIMENTOS}

Ao Dr. Sérgio Augusto Carbonell, do Instituto Agronômico de Campinas, e à Dra. Marlene Silva Freire, da Embrapa Arroz e Feijão, pelo fornecimento de sementes dos diferentes genótipos de feijoeiro e ao PRONEX/FINEP, pelo auxílio financeiro.

\section{REFERÊNCIAS BIBLIOGRÁFICAS}

CHAVARRO, C.A., LOPEZ, G.C.A. \& LENNE, J.M. Características y pathogenicidad de Corynebacterium flaccumfaciens (Hedges) Dows. agente causal del marchitamiento bacteriano de Zornia spp. y su efecto en el rendimiento de Z. glaba CIAT 7847 y Phaseolus vulgaris. Acta Agronomica 35:64-79. 1985.

COYNE, D.P., SCHUSTER, M.L. \& AL-YASIRI, S. Reaction studies of bean species and varieties to common blight and bacterial wilt. Plant Disease Reporter 47:534-537. 1963.

COYNE, D.P., SCHUSTER, M.L. \& YOUNG, J.O. A genetic study of bacterial wilt (Corynebacterium flaccumfaciens var. aurantiacum) tolerance in Phaseolus vulgaris crosses and the development of tolerance to two bacterial diseases. American Society for Horticultural Science 87:279-285. 1965.

COYNE, D.B., SCHUSTER, M.L. \& ESTES, L.W. Effect of maturity and environment on the genetic control or reaction to wilt bacterium in Phaseolus vulgaris L. American Society for Horticultural Science.88:393-399. 1966.

COYNE, D.P. \& SCHUSTER, M.L. Breeding and genetic studies of tolerance to several bean (Phaseolus vulgaris L.) bacterial pathogens. Euphytica 23:651-656. 1974.

DINENSEN, I.G. The movement of Corynebacterium flaccumfaciens in bean plants. In: Anais, IV International Conference on Plant Pathogenic Bacteria, Angers, 1978. pp.929-933.

HALLUKA, M., SCHUSTER, M.L., WEIHING, J.C. \& COYNE, D.P. Population trends of Corynebacterium flaccumfaciens strain in leaves of Phaseolus species. Fitopatologia Brasileira 3:13-26. 1978.

HEDGES, F. Bacterial wilt of beans (Bacterium flaccumfaciens Hedges), including comparisons with Bacterium phaseoli. Phytopathology 16:1-22. 1926.

KARKMKOVA, P. \& BOYADZHIEV, K.H. The new garden bean cultivar Rositsa. Gardinaska i Lozarka Nauka 21:40-43. 1984.

MARINGONI, A.C. \& ROSA, E.F. Ocorrência de Curtobacterium flaccumfaciens pv. flaccumfaciens em feijoeiro no Estado de São Paulo. Summa Phytopathologica 23:160-162. 1997.

MARINGONI, A.C. Virulência de isolados de Xanthomonas campestris pv. phaseoli (Smith) Dye em feijoeiro. Pesquisa Agropecuária Brasileira 33:861-867. 1998.

MARINGONI, A.C. Caracterização de isolados de Curtobacterium flaccumfaciens pv. flaccumfaciens e avaliação da resistência de cultivares de feijoeiro comum à murcha-de-Curtobacterium. (Tese de Livre-Docência). Botucatu. Faculdade de Ciências Agronômicas - UNESP. 2000.

NIKITINA, K.V., BUDANOVA, V.I., STEPANOVA, S.I. \& YASKINA, O.S. Rapid method of evaluating resistance to bacterial diseases in lupin and Phaseolus. Selektsiya i Semenovodstvo URSS 5:22-23. 1980.

PHANG, P.D., GUTENMAHER, P. \& MOELA, I. Resistance to bacterial rots in some French bean. Lucrari Stiintifice A 17:4548. 1974.

POMPEU, A.S. Cultivares de feijoeiro Bico de Ouro e Carioca Pyatã. Campinas. Instituto Agronômico. 1994.

POMPEU, A.S. Cultivares de feijoeiro IAC Carioca Aruã e IAC 
Carioca Akytã. Campinas. Instituto Agronômico. 1996.

RAVA, C.A. \& SARTORATO, A. Crestamento bacteriano comum. In: Sartorato, A. \& Rava, C.A. (Eds.) Principais doenças do feijoeiro e seu controle. Brasília. Empresa Brasileira de Pesquisa Agropecuária. 1994. pp.217-242.

ROBBS, C.F., RODRIGUES NETO, J., RIBEIRO, R.L.D. \& KIMURA, O. Annotated list of bacterial plant pathogens in Brazil. In: Anais, V International Conference on Plant Pathogenic Bacteria, Cali, 1982. pp.601-613.

SAETTLER, A.W. \& PERRY, S.K. Seed-transmited bacterial diseases in michigan navy (pea) beans, Phaseolus vulgaris. Plant Disease Reporter 56:378-381. 1972.

SAETTLER, A.W. Diseases caused by bacteria. In: Hall, R. (Ed.) Compendium of bean diseases. St. Paul. American Phytopathological Society. 1991. pp.29-32.
SCHUSTER, M.L., COYNE, D.P. \& SING, K. Population trends and movement of Corynebacterium flaccumfaciens var. aurantiacum in tolerant and susceptible beans. Plant Disease Reporter 48:823-827. 1964.

TORRES, J.P. \& MARINGONI A.C. Métodos de inoculação, estádios de desenvolvimento fenológico da planta e reação de cultivares de feijoeiro a Xanthomonas axonopodis pv.phaseoli. Ciência e Agrotecnologia 23:124-129. 1999.

SCHOONHOVEN, A. van \& PASTOR-CORRALES, M.A. Sistema estándar para la evaluación de germoplasma de frijol. Cali. Centro Internacional de Agricultura Tropical. 1987.

VENETTE, J.R., LAMPRA, R.S. \& GROSS, P.L. First report of bean bacterial wilt caused by Curtobacterium flaccumfaciens subsp. flaccumfaciens in North Dakota. Plant Disease 79:966. 1995. 